\title{
ESTUDO DO PERFIL SOCIOECONÔMICO DAS COMUNIDADES DO ENTORNO DO PARQUE ESTADUAL DA LAGOA DO AÇU, RJ.
}

\author{
Kelly Pinheiro dos Santos ${ }^{1}$ \\ Luiz de Pinedo Quinto Junior ${ }^{2}$ \\ Vicente de Paulo Santos de Oliveira ${ }^{3}$
}

\section{Resumo}

Com a crescente industrialização, após a revolução industrial o homem tem promovido uma série de transformações, tanto ambientais quanto sociais. Sendo estabelecidos alguns critérios e normas para criação, implantação e gestão das unidades de conservação no Brasil de forma integrada. Entretanto essas normas e critérios têm provocado uma série de conflitos enfrentados pelos gestores. Diante desses conflitos, e visando caracterizar o perfil socioeconômico, foram aplicados questionários semiestruturados em três das comunidades próximas ao Parque Estadual da Lagoa do Açu, em que os resultados apontam para um distanciamento da população local com a implantação deste, uma vez que a maioria dos entrevistados não conhece o parque e classificam sua implantação como sendo ruim. Desta forma, a articulação entre o poder público e a sociedade civil e a gestão compartilhada seriam formas de minimizar os conflitos.

Palavras-chave: Unidade de Conservação, Parque Estadual da Lagoa do Açu, Perfil socioeconômico.

\begin{abstract}
With increasing industrialization, after the industrial revolution man has promoted a series of changes, both environmental and social. It is established some criteria and standards for the creation, deployment and management of protected areas in Brazil in an integrated manner. However those standards and criteria have led to a series of conflicts faced by managers. Faced with these conflicts, and to characterize the socioeconomic profile, semi-structured questionnaires were applied in three communities near the State Park Açu Lagoon, where the results point to a distancing of the local population with the implementation of this, since most respondents did not know the park and rate their implementation as bad. Thus, the relationship between the government and civil society and the shared management would be ways to minimize conflicts.
\end{abstract}

Keywords: Protected field, Açu Lagoon State Park, Socioeconomic Profile

\footnotetext{
${ }^{1}$ Bióloga, pela Universidade Estadual do Norte Fluminense/UENF, especialista em Educação Ambiental pela Faculdade do Noroeste de Minas/FINOM, mestranda em Engenharia Ambiental pelo Instituto Federal de Educação, Ciência e Tecnologia Fluminense, IF Fluminense campus Macaé, RJ. Email: $\underline{\text { Kellypinheiros@yahoo.com.br }}$

2 Doutor em Arquitetura e Urbanismo pela Universidade de São Paulo/ USP. Professor do Instituto Federal Fluminense.

3 Doutor em Engenharia Agrícola pela Universidade Federal de Viçosa/ UFV. Professor do Instituto Federal Fluminense.
} 


\section{Introdução e caracterização da área de estudo}

A partir da revolução industrial no século XVIII, com a crescente industrialização, é promovida uma série de transformações tanto sociais como ambientais, motivando o uso indiscriminado dos recursos naturais, causando transformações significativas no meio ambiente e na sociedade. Essas transformações perpassam até os dias atuais.

O Brasil, país com altíssima biodiversidade, conta com o Sistema Nacional de Unidades de Conservação (SNUC), instituído pela Lei $\mathrm{n}^{\circ}$ 9.985, de 18 de Julho de 2000, que estabelece os critérios e normas para criação, implantação e gestão das unidades de conservação (UCs) de forma integrada, visando, dentre outros objetivos, contribuir para a manutenção e restauração da diversidade biológica dos ecossistemas naturais, promoverem o desenvolvimento sustentável e proteger paisagens naturais e pouco alteradas de notável beleza cênica (BRASIL, 2000). Entretanto, um dos principais problemas enfrentados pelos gestores das UCs é o conflito envolvendo o manejo da área preservada e a população que se encontra nas proximidades destas unidades. Esses conflitos surgem porque cada indivíduo envolvido na UC, seja ele gestor, visitante ou pesquisador, tem sua própria percepção e vivência (GONÇALVES e HOFFEL, 2012). Na maioria das vezes os conflitos maiores ocorrem onde já existem comunidades consolidadas, como é o caso das localidades estudadas de Quixaba, Maria da Rosa e Xexé. De acordo com Shiraishi (2011), os conflitos relacionados ao uso de destinação dos recursos naturais sempre estarão presentes em qualquer escala ou tipo de ocupação humana constituindo parte do processo de construção e reconstrução social.

O Parque Estadual da Lagoa do Açu (PELAG), área estudada, encontra-se localizado entre os municípios de São João da Barra e Campos dos Goytacazes, na baixada de Campos dos Goytacazes. Este foi criado pelo decreto estadual de número 43.522 de 20 de março de 2012. Sendo sua implantação de responsabilidade do governo estadual e relacionada como uma das formas de compensação ambiental do entorno do empreendimento do grupo EBX, responsáveis pela implantação do Complexo Industrial Portuário do Açu (SILVA \& RANGEL 2014). Este tem como um dos objetivos protegerem os alagados e brejos situados ao norte da estrada Campos-Farol de São Tomé, uma parte do canal Quitingute, a Lagoa do Açu, parte da Lagoa Salgada e os remanescentes de restinga entre a Lagoa Salgada e o Farol de São Tomé.

De acordo com Costa (2013) a proposta inicial do parque (Figura 01) abrangia a área entre a Lagoa de Grussaí e a Restinga do Xexé, em Farol de São Tomé. Atualmente o parque engloba o Banhado da Boa Vista, a Lagoa do Açu e um trecho da Lagoa Salgada. Devido à grande diversidade ambiental existente na Lagoa Salgada e o mangue, existem propostas para que estas sejam inseridas na área do parque.

Figura 01 - Delimitação da área do Parque Estadual da Lagoa do Açu 


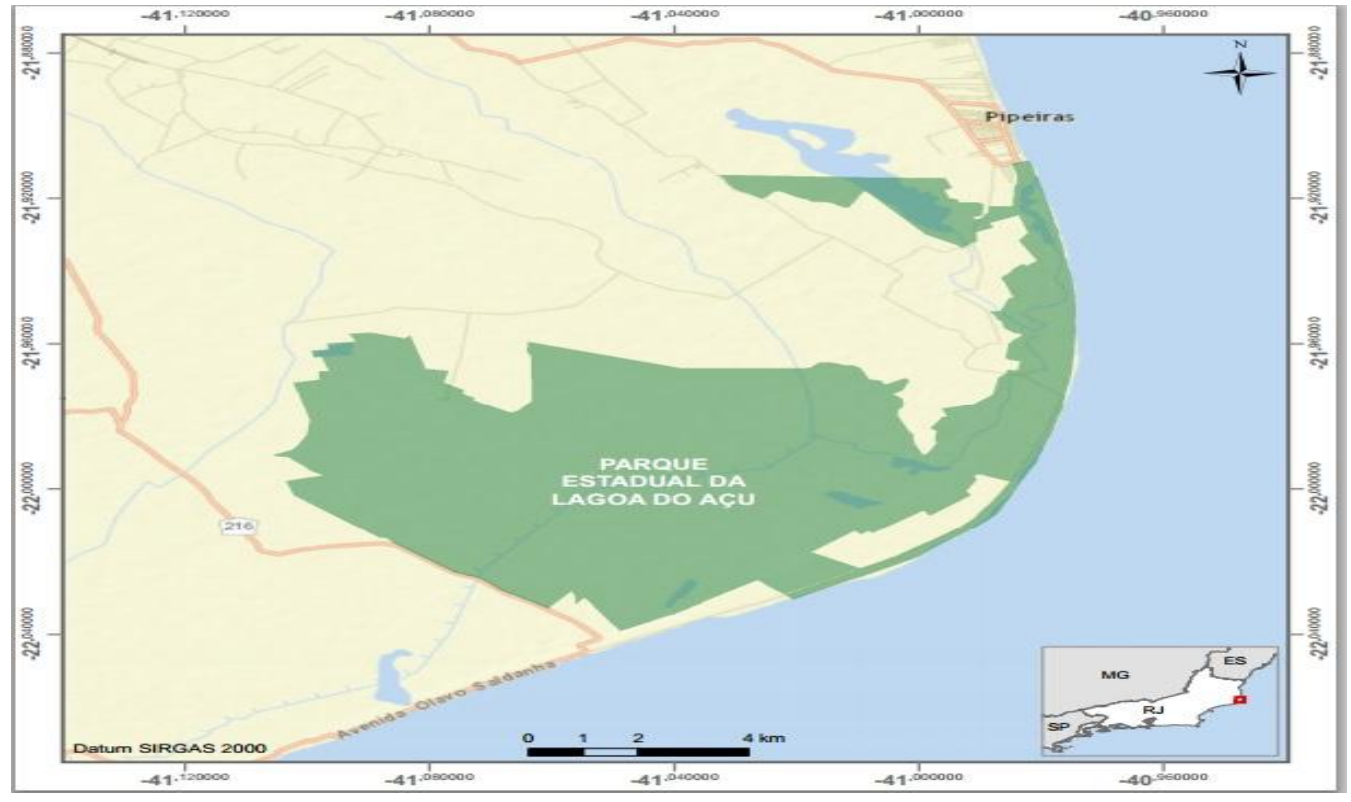

O PELAG possui 8.251 hectares, mais que o dobro do Parque Nacional da Tijuca (RJ), abriga importantes áreas de restinga e uma extensa faixa de praia (INEA, 2014), Este é classificado como uma UC de proteção integral, assegurando a preservação de remanescentes de vegetação nativa de mata atlântica como restinga, mangue e uma importante área alagada, o banhado de Boa Vista, além da Lagoa do Açu, com $13 \mathrm{~km}$ de extensão no litoral. Sua existência ajuda na integração de seus ecossistemas com a diversidade sociocultural da região, além da preservação de espécies raras, endêmicas e ameaçadas de extinção, da flora e da flora. Além dessas áreas inclui parte da Lagoa Salgada que abriga as únicas ocorrências de estromatólitos carbonáticos que podem ser definidos como estruturas biossedimentares litificadas, que crescem através do acréscimo de lâminas de sedimentos aprisionados pela precipitação de carbonato como resultado da atividade de organismos microbianos (SILVA e SILVA, 2002).

A população que habita essa área e arredores é composta por comunidades rurais, pescadores artesanais, agricultores familiares, posseiros e pequenos comerciantes (KURY, REZENDE, PEDLOWSKI, 2010). Além desses, há os habitantes temporários, que frequentam a região na estação de veraneio, atraídos pelas praias locais e pelo clima. Desta forma, o envolvimento da população local é um elemento importante que precisa ser incorporado nas estratégias de manejo da conservação para que os grupos locais adquiram capacidade de formular e alcançar os seus próprios objetivos de desenvolvimento em conformidade com a preservação local é preciso que haja a participação de todos os atores (PRIMACK \& RODRIGUES, 2001).

Apesar da relevância existente na relação homem-natureza, poucos são os trabalhos científicos encontrados sobre este assunto. O Parque Estadual da Lagoa do Açu localizado entre os municípios de Campos dos Goytacazes e São João da Barra, ainda não possui Plano de Manejo, que constitui um importante instrumento de planejamento e gestão. Diante desse cenário, este trabalho teve como objetivos identificar o perfil socioeconômico de algumas 
comunidades ao entorno desse parque, a fim de se conhecer os significados e atitudes que regem as relações estabelecidas pela comunidade rural do entorno deste parque com os elementos naturais e a UC.

Os resultados desse estudo serão fundamentais para subsidiar a elaboração do Plano de Manejo desta UC e para o envolvimento dessa comunidade na conservação e utilização sustentável dos recursos naturais provenientes do parque.

\section{Material e métodos}

Este trabalho apresenta uma característica exploratória e analítica. Além da pesquisa bibliográfica e documental, foi realizada uma pesquisa de campo, com aplicação de questionários semiestruturados, objetivando-se identificar o perfil socioeconômico da população residente da área do entorno. Para realização do estudo, foram utilizados como material de pesquisa, máquina fotográfica, computador, gravador, mapas e os questionários.

Os questionários foram aplicados na população da Quixaba, Xexé, e Maria da Rosa (Figura 2) três das localidades afetadas com o Parque Estadual da Lagoa do Açu, sendo a estratégia adotada nessa pesquisa a aplicação do questionário com entrevista, de forma a garantir maior flexibilidade nas perguntas e possibilitar o esclarecimento e aprofundamento de algumas questões (ARRUDA, 2011). As questões foram ordenadas em sequência lógica, objetivando caracterizar o perfil socioeconômico do entrevistado, bem como sua percepção ambiental em relação à criação do Parque Estadual da Lagoa do Açu.

Figura 02 - Localidades pesquisadas

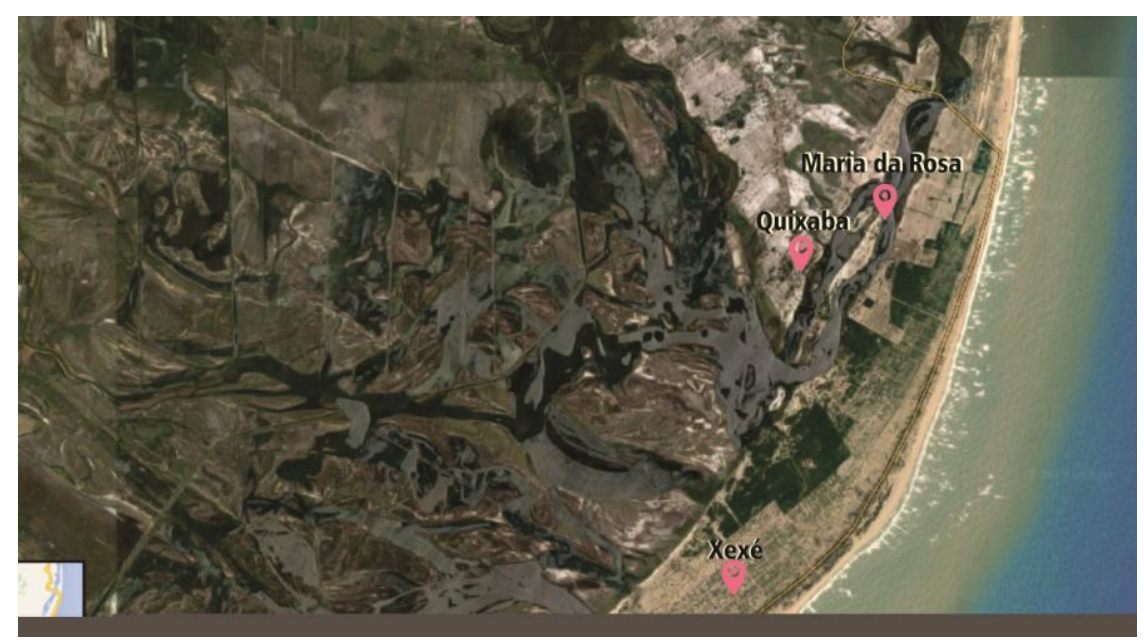

Ressalta-se, ainda, que para a escolha dos entrevistados foi levada em consideração uma amostragem aleatória simples, adotado um nível de confiança de 97\% e uma margem de erro de 7,5\% na obtenção do tamanho da amostra.

A partir da equação (1) apresentada por Agresti e Finlay (2009), foi determinado o número $\mathrm{n}$ de pessoas a serem entrevistadas.

$$
\mathrm{n}=\pi(1-\pi)\{\mathrm{z} / \mathrm{M}\}^{2}
$$


onde $\pi$ é a proporção inicialmente adotada como resposta aos questionamentos da pesquisa, $\mathrm{z}$ é o valor da distribuição normal associado ao nível de confiança adotado e $M$ é a margem de erro. Para a proporção, foi utilizada uma estimativa de $50 \%$, de modo a garantir uma amostragem mais segura, já que resulta em uma amostra maior, e o z, para o nível de confiança de $97 \%$, é 1,96. Diante da população estimada da Quixaba e Xexé de 850 habitantes, conforme apresentado pela agente comunitária das localidades, chega-se ao número de 171 questionários a serem aplicados em cada comunidade. A quantidade de moradores da comunidade da Maria da Rosa não foi possível ser estimada, visto que os dados não estão registrados no IBGE e nem com agentes de saúde, sendo aplicados dessa forma 30 questionários. Inicialmente, foi elaborado um questionário piloto com caráter qualitativo, de forma a identificar as alterações necessárias a serem feitas para se obter uma versão definitiva.

Dessa forma, foram elaboradas três versões do questionário, em que foram acrescentadas algumas questões que, a partir das respostas do questionário piloto, percebeu-se serem temáticas que necessitavam de maior aprofundamento, e retiradas outras que já estavam contempladas na resposta de perguntas anteriores. A cada versão, foi realizado um teste de aplicação com a população visando à adequação às novas necessidades da pesquisa. $\mathrm{O}$ questionário deixou, então, de ser unicamente qualitativo e passou a ser predominantemente quantitativo com o intuito de facilitar a tabulação dos resultados.

\section{Resultados}

O estudo do perfil socioeconômico visa perceber como a população local (PL) das três comunidades é constituída, sendo analisado o sexo, o tempo de residência, a escolaridade e a renda salarial (Quadro 1). Além disso, pode-se analisar a quantidade familiar e o modo de vida dos habitantes da região.

Dentre os 472 entrevistados a maioria foi de sexo feminino. No que diz respeito ao tempo de moradia na comunidade, a maioria da população entrevistada mora no entorno do PELAG a mais de 40 anos, na região da Quixaba e de 20 a 40 anos em Maria da Rosa e Xexé. As famílias das três comunidades são constituídas geralmente de 3 a 4 indivíduos por núcleo familiar. Os dados sobre escolaridade demonstram que a maioria dos entrevistados possui o nível fundamental, seguidos por aqueles que não sabem ler e nem escrever.

Quadro I - Perfil Socioeconômico das comunidades

\begin{tabular}{l|cc|cc|cc}
\hline Localidade & \multicolumn{3}{|c|}{ Quixaba } & \multicolumn{2}{c}{ Maria da Rosa } & \multicolumn{2}{c}{ Xexé } \\
& PL & $\%$ & PL & \% & PL & \% \\
\hline
\end{tabular}




\begin{tabular}{|c|c|c|c|c|c|c|}
\hline $\begin{array}{l}\quad \underline{\text { Sexo }} \\
\text { Feminino } \\
\text { Masculino }\end{array}$ & $\begin{array}{l}95 \\
76\end{array}$ & $\begin{array}{l}55 \\
45\end{array}$ & $\begin{array}{l}21 \\
9\end{array}$ & $\begin{array}{l}70 \\
30\end{array}$ & $\begin{array}{l}68 \\
103\end{array}$ & $\begin{array}{l}40 \\
60\end{array}$ \\
\hline $\begin{array}{l}\frac{\text { Tempo que reside no }}{\underline{\text { local }}} \\
\text { Até } 5 \text { anos } \\
\text { De } 5 \text { a } 20 \text { anos } \\
\text { De } 20 \text { a } 40 \text { anos } \\
\text { Mais de } 40 \text { anos }\end{array}$ & $\begin{array}{r}9 \\
43 \\
43 \\
76\end{array}$ & $\begin{array}{r}5 \\
25 \\
25 \\
45\end{array}$ & $\begin{array}{l}- \\
6 \\
15 \\
9\end{array}$ & $\begin{array}{c}- \\
20 \\
50 \\
30\end{array}$ & $\begin{array}{r}9 \\
26 \\
76 \\
60\end{array}$ & $\begin{array}{r}5 \\
15 \\
45 \\
35\end{array}$ \\
\hline $\begin{array}{l}\quad \text { Escolaridade } \\
\text { Sabe ler e escrever } \\
\text { Ensino fundamental } \\
\text { Ensino médio } \\
\text { Ensino técnico } \\
\text { Ensino superior }\end{array}$ & $\begin{array}{l}26 \\
145 \\
- \\
- \\
-\end{array}$ & $\begin{array}{r}15 \\
85 \\
- \\
- \\
-\end{array}$ & $\begin{array}{l}12 \\
18 \\
- \\
- \\
-\end{array}$ & $\begin{array}{l}40 \\
60 \\
- \\
-\end{array}$ & $\begin{array}{l}60 \\
76 \\
34 \\
- \\
-\end{array}$ & $\begin{array}{l}35 \\
45 \\
20 \\
- \\
-\end{array}$ \\
\hline $\begin{array}{l}\text { Renda familiar } \\
\text { Até } 1 \text { salário } \\
\text { mínimo }\end{array}$ & 111 & 65 & 21 & 70 & 103 & 60 \\
\hline $\begin{array}{l}\text { Até } 2 \text { salários } \\
\text { mínimos }\end{array}$ & 51 & 30 & 9 & 30 & 68 & 40 \\
\hline $\begin{array}{l}\text { Até } 3 \text { salários } \\
\text { mínimos }\end{array}$ & 9 & 5 & - & - & - & - \\
\hline $\begin{array}{l}\text { Acima de } 3 \text { salários } \\
\text { mínimos }\end{array}$ & - & - & - & - & - & - \\
\hline $\begin{array}{c}\text { Total de } \\
\text { entrevistados }\end{array}$ & 171 & 100 & 30 & 100 & 171 & 100 \\
\hline
\end{tabular}

Além disso, grande parte da população não possui carteira assinada tendo como principais fontes de renda a pesca e a confecção de esteira (Figura 03), artesanato feito da folha da Taboa ${ }^{4}$, na Quixaba e Maria da Rosa e o comércio no Xexé. Segundo os moradores, a cultura de artesanato é transmitida de geração para geração e as famílias sobrevivem durante anos desta atividade econômica.

\footnotetext{
${ }^{4}$ Taboa (Typha domingensis) é uma planta hidrófita (aquática) típica de brejos, manguezais, várzeas e outros espelhos de águas. Mede cerca de dois metros e na época de reprodução apresenta espigas da cor café contendo milhões de sementes que se espalham pelo vento.
} 
Figura 03 - Equipamento para confecção de esteira.

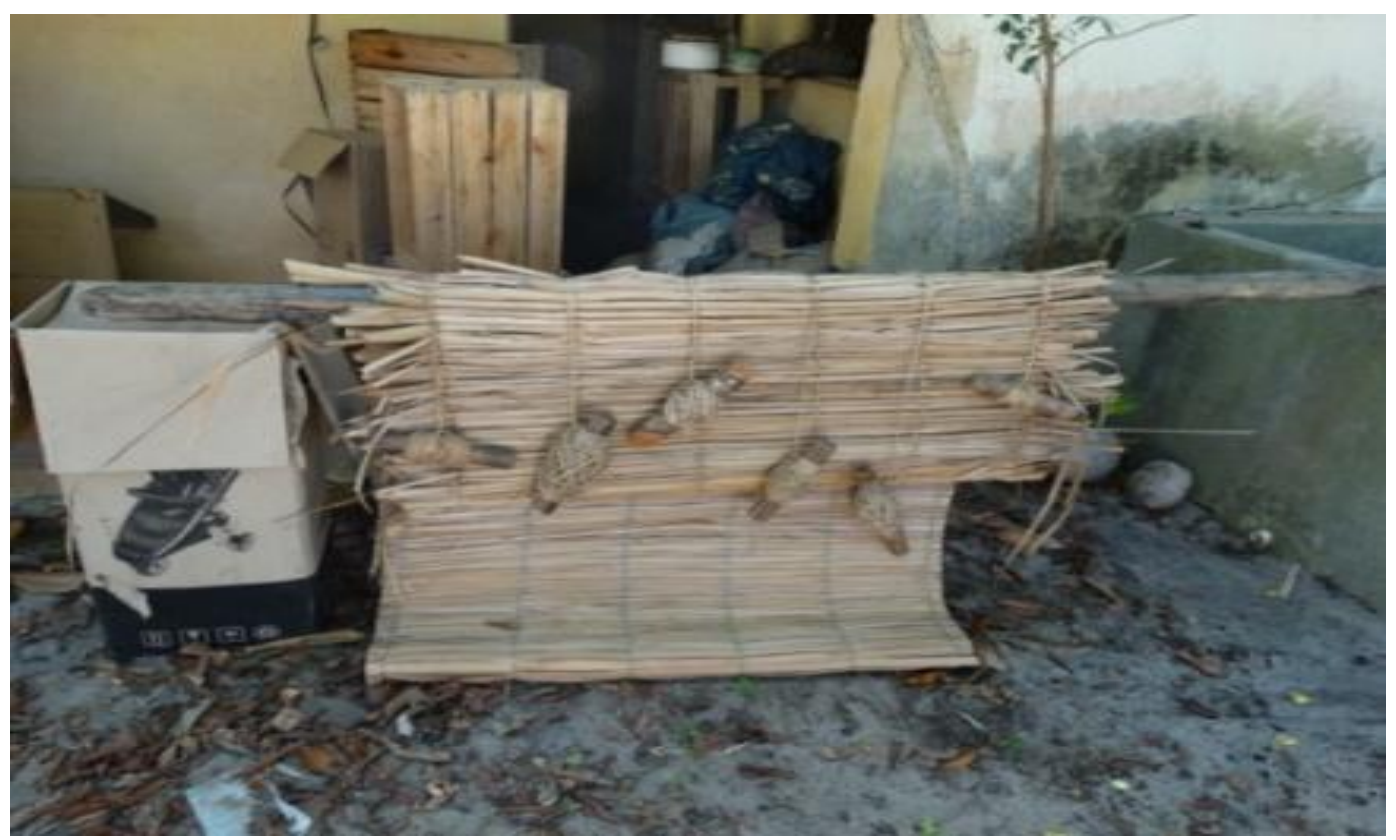

Autoria: Kelly Pinheiro dos Santos

A renda familiar da maioria da população local, é no máximo de 1 salário mínimo. De acordo com relato de uma das moradoras da Maria da Rosa, sua renda mensal é de $\mathrm{R} \$ 300,00$ por mês. Esta sobrevive da venda de esteiras, vendendo cada uma por R $\$ 3,00$.

As comunidades, principalmente Quixaba e Maria da Rosa, possuem um aspecto de ambiente rural, com diversas plantações e a presença de animais na região. Geralmente as moradias dessas comunidades são simples (Figura 04), revelando, assim sua principal característica local. As condições sanitárias são precárias uma vez que não possuem rede de saneamento básico, os efluentes são lançados a céu aberto ou diretamente nas lagoas.

Figura 04 - A- Moradias nas comunidades de Maria da Rosa. B- Moradias nas comunidades Quixaba. 


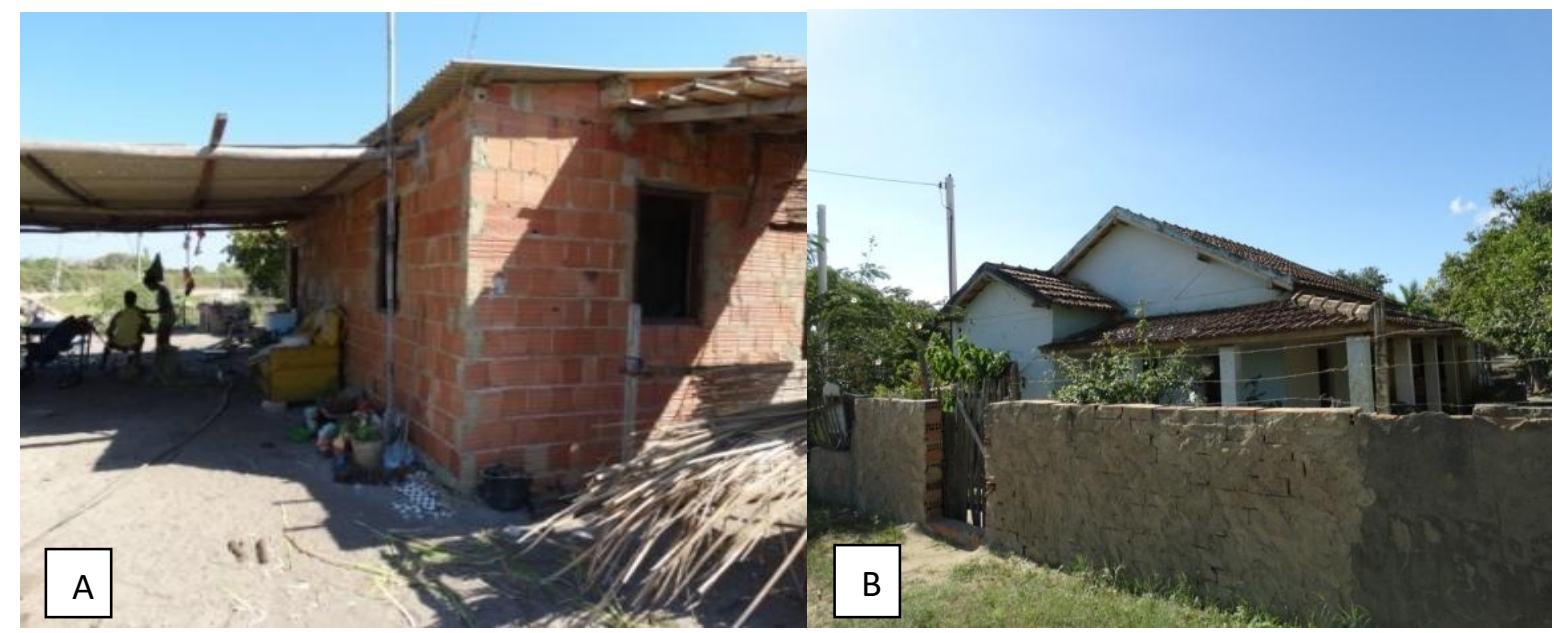

Autoria: Kelly Pinheiro dos Santos

\section{Conclusão}

De acordo com os resultados obtidos nesta pesquisa pode-se inferir que a maioria dos entrevistados das três comunidades foi de sexo feminino, residindo na localidade há mais de 40 anos na região da Quixaba e 20 a 40 anos na Maria da Rosa e Xexé, tendo como escolaridade o nível fundamental. Além disso, foi demonstrado que grande parte da população não possui carteira assinada recebendo como renda familiar até 1 salário mínimo. As comunidades possuem um aspecto de ambiente rural, onde as condições sanitárias são precárias, pois não possuem rede de saneamento básico.

\section{Referências bibliográficas}

AGRESTI,A; FINLAY, B. Statistical Methods for the Social Sciences. Pearson/Prentice Hall. 2009. 609 p.

ARRUDA, D. A política regional no Brasil: Uma análise dos planos para o partir da visão sistêmica. Cadernos do Desenvolvimento. Rio de Janeiro, v.6 n. 9, p. 61-91, jul./dez. 2011.

BIDEGAIN, P. Lagoas do Norte Fluminense: perfil ambiental. Rio de Janeiro: Fundação Superintendência de Rios e Lagoas (SERLA), 2002. 148 p. (Boletim, 14);

BRASIL. (2000) Lei no 9.985, de 18 de Julho de 2000. Institui o Sistema Nacional de Unidades de Conservação da Natureza. Brasília.

COSTA,M.B. Uso cobertura do solo do Parque Estadual da Lagoa do Açu.Dissertação( mestrado). Instituto Federal Fluminense, RJ.2013.

GONÇALVES, N. M.;HOEFFEL,J.L.M. Percepção ambiental sobre unidades de conservação: os conflitos em torno do Parque Estadual de Itapetinga- SP. Revista VitasVisões Transdiciplinares sobre ambiente e sociedade. ISSN 2238-1627 n $\mathrm{n}^{\mathbf{0}}$ 3, 2012. Disponível em < www.uff.br/revistavitas.htm > Acesso: 10/04/2014. 
INEA. Parque Estadual da Lagoa do Açu . Disponível em:

http://www.inea.rj.gov.br/Portal/Agendas/BIODIVERSIDADEEAREASPROTEGIDAS/ . Acesso : 20/11/2014

KURY, K. A., REZENDE, C. E., PEDLOWSKI, M.A. (2010). O Entendimento da População de São João da Barra sobre a Influência do Mega-empreendimento do Complexo Portuário e Industrial do Açu em seu Cotidiano. V Encontro Nacional da Anppas. Florianópolis - SC.

PRIMACK, R.B.; RODRIGUES,E. (2001) Biologia da Conservação. Londrina: Efraim Rodrigues.

SILVA E SILVA, L.H. 2002. Contribuição ao conhecimento da composição microbiana e química das estruturas estromatolíticas da lagoa Salgada, Quaternário do Rio de Janeiro, Brasil. Programa de Pósgraduação em Geologia, Universidade Federal do Rio de Janeiro, Tese de Doutorado, 176p.

SILVA, I.R; Rangel,T.A. Impactos sociais, econômicos, culturais e ambientais provocados pela implantação do CLIPA e PELAG na comunidade de Alto Cardeiro, município de São João da Barra/RJ. Monografia (graduação em geografia). Instituto Federal Fluminense, RJ 2014.

SHIRAISH, J, C. Conflitos ambientais em unidades de conservação: Percepções sobre a reserva biológica de Contagem, DF. 2011. Dissertação (mestrado em Desenvolvimento sustentável). Centro de desenvolvimento sustentável. Universidade de Brasília, Brasília. 